\title{
030 An Education of Intuition and Process: Learning Architectural Design at Hong Kong Design Institute
}

\section{Eddie Chan}

$166-181$

This paper is a positioning statement and expository article describing design and fabrication projects built by students and faculty of the Hong Kong Design Institute's (HKDI's) Architecture programme. Through a series of experimental design-build projects, HKDI faculty teaches students the knowledge and experience to be gained through personal fabrication work, whether wholly manual or digitally assisted. The author stages the work against a series of excerpts from notable architects' writings, describing a field of study relating tacit knowledge, architectural education, and fabrication specifics students explore through projects in Hong Kong and South China. Lessons and summary bodies of knowledge drawn from these preliminary projects define the path forward for HKDI's spatial design pedagogy and research.

\footnotetext{
\#architecture education

\#fabrication

\#making

\#hong kong
} 


\section{Introduction: Intellectual Precedents}

Learning a skill is not primarily founded on verbal teaching, but rather on the transference of the skill from the muscles of the teacher directly to the muscles of the apprentice through the act of sensory perception and bodily mimesis. This capacity of mimetic learning is currently attributed to human mirror neurons. The same principle of embodying - or introjecting, to use a notion of psychoanalytic theory-knowledge and skill continues to be the core of artistic learning. The foremost skill of the architect is, likewise, to turn the multi-dimensional essence of the design task into embodied and lived sensations and images; eventually the entire personality and body of the designer becomes the site of the design task, and the task is lived rather than understood (Pallasmaa 2009).

My own suspicion of the enormous generative part played by architectural drawing stems from a brief period of teaching in an art college. Bringing with me the conviction that architecture and the visual arts were closely allied, I was soon struck by what seemed at the time the peculiar disadvantage under which architects labour, never working directly with the object of their thought, always working at it through some intervening medium, almost always the drawing, while painters and sculptors, who might spend some time on preliminary sketches and maquettes, all ended up working on the thing itself which, naturally, absorbed most of their attention and effort (Evans 1996).

Precision can be about the tolerances involved in components, while accuracy is an instinctive thing. Precision has to do with the skill of crafting, whereas accuracy is about how fine the instinctive understanding may be. No matter how you hone and tune it, accuracy remains a kind of gut reaction. When people enter a space, they should be able to feel it as well. It's the difference between something learned and a talent (Salter 1989).

\section{Architecture and Architecture Education}

As an architecture student, it is an inevitable part of the journey that one must make models, collages, prototypes, etc. Yet, once the student graduates and enters the professional environment, it is common to find that most of the working hours are spent on digital work in front of a computer. Architectural models and prototypes are often produced by in-house or contracted model makers for presentation purposes, not as an integrated part of the design exercise. Why, then, is making, the hands-on experience, still an essential part of architectural education?

The three excerpts above summarise views on architecture and architecture education in relation to making and physical, hands-on, experience. To borrow Peter Salter's interpretation (ibid.) of the two terms, architecture is a practice that demands a high level of precision in its construction, and accuracy in its design sensitivity. It is a profession that requires a rational mindset as well as an artistic one. Although architecture is often associated with other artistic practices, unlike other artists, as Robin Evans (Evans 1986) observed, architects seldom have first-hand experience in actualising their work. Architects rely on a large team of builders, craftsmen and technicians to realise their work.

At school, we learn architecture by reading, writing, drawing, modelling and visiting exemplar architecture. Students represent research and design proposals in text, scaled drawings, and fragmented models. Through these media, we learn to communicate with others the physical construction of architecture as well as the spatial quality of the spaces we design. Understanding 
architecture through these texts, drawings and models is like reading a piece of music without hearing it: it is a rather inconvenient form of communication that requires a good deal of imagination and articulation of thoughts to mentally compose a holistic image of the envisioned architecture. Until the conceived architecture is realised, most of the envisioned architectural quality is speculative. It is unlikely to bring an architecture to reality if the speculative representation of its vision fails to convince the client. As such, making through direct, physical engagement with the subject matter is vital and effective to build up students' abilities to bridge the gap between concept and realisation.

As Juhani Pallasmaa (Pallasmaa op. cit.) pointed out, acquiring knowledge is an experiential process. If a student is to learn how to design with brick, it is insufficient to merely read books or attend lectures. She or he should be encouraged to gain first-hand experience by visiting a brick factory; going down to a clay pit; seeing how water is pressed out of the clay; learning how to form a brick from the mould; feeling the difference between a dry brick ready to be fired and a brick fresh from the mould; examining the colour variations of bricks from the kiln; breaking a brick with a hammer; soaking a brick in water; mixing mortar; building a brick wall; building a brick arch; surveying as much brick architecture as possible.

Even though the student still has no experience in designing brick architecture, one would be convinced that he or she has a good amount of academic knowledge and practical experience about the material and what it can do. More likely she or he should be able to design in brick. Furthermore, if the student has learnt to make such in-depth inquiry on one subject matter, one would expect that the same person can apply a similar methodology to learn about timber architecture, concrete architecture, or other building technologies.

\section{Introducing the Culture of Making at HKDI}

"We learn how to build by building," my tutor Michele Roelofsma used to say. There is a fundamental difference between an architect who enjoys making and an artisan or a craftsman. When an architect makes an object, however beautiful the object might be as a work of art or craft, it always carries a meaning beyond the object itself that feeds back to the architecture discourse. Mario Bellini (cf. Bellini, Business of Design Week 2017) once said that he enjoyed designing furniture, and out of all types of furniture, he enjoyed designing tables the most because he felt that a table was like a miniature building In a similar cross-disciplinary translation, architects rely heavily on making of objects as an intervening medium to sharpen their aesthetics and our understanding of space, materiality, and human habitation. They observe the world via the objects we make. Architects test and evaluate the accuracy of our instinctive understanding of the world through materialising our ideas in various scales and media. As a part of architectural education, it is important to encourage students to make. It is more important that the made objects are put to the test in real situations so that students can evaluate their designs and vision against the complete process and outcome. Full-size construction is essential to provide such evaluation opportunities. The projects selected for this paper are full-size live projects that cover a variety of scales and design-construction methods. Some are designed and fabricated almost entirely by digital tools. Some are done almost entirely by manual labour with a construct and improvise methodology. Each project has its unique process and each of them informs us of something valuable about the teaching and learning of architecture. The design-construction processes of the projects are summarised in Table 1. 


\section{Oil Street Bamboo Installation Project Leader: Eddie Chan. \\ Project Type: Public Participation Design Workshop. Duration: 4 days (2 weekend workshops).}

The Oil Street Bamboo Installation looked at traditional Chinese handicraft using bamboo splits and paper joints that are common in the making of festive products, such as paper lanterns and bamboo decorations for Chinese New Year and Mid-Autumn Festival. The basic skills of this craft are easy to learn. Therefore, it is possible for almost anyone to engage and participate. The design potential lies in the flexibility and lightness of the material. Five students and ten local participants hand-wove a bamboo mesh of 2 $x 8$ meters in three days, before playing with the mesh to see what forms could be achieved for the final installation (Fig. 1).

\section{Halo Modular Unit}

Project Leader: Eddie Chan, Paul Mui.

Project Type: Student Competition +. Post competition development.

Duration: 2 weeks competition +2 months post development.

Sponsor: Halo Creative \& Design Limited.

The Halo Modular Unit was a student design competition for a prototype of mobile living unit that was transportable and easily assembled. The winning design was a flat-pack architecture module consisting of four standardised panels and six joining members that could all be digitally fabricated. On-site installation is designed to be quick and machine-less, almost like scaled-up Ikea furniture (Fig. 2).

\author{
Very Hong Kong Installation and the Tamar \\ Park Installation \\ Project Leader: Eddie Chan, Jason Tang. \\ Project Tutor: Susanna Wong, Thomas Chan. \\ Project type: Design Studio. \\ Duration: 8 weeks (Design + Construction).
}

Students built the Very Hong Kong Installation and Tamar Park Installation under the digital design studio Pattern to Fabrication. The design studio explored how patterns were used in architecture from traditional two-dimensional motifs to contemporary three-dimensional façade design. With the help of parametric tools, a componentbased design was applied to the two projects that used standardised plywood and recycled timber planks as construction materials (Fig. 3-5).

\section{Meinan Village Bamboo Pavilion}

Project Leader: Eddie Chan, Kuo Jze Yi . Project type: Summer Studio + Workshop. Duration: 7 weeks ( 5 weeks Design +2 weeks Construction).

The Meinan Village Bamboo Pavilion project was an intensive design and construction studio in which the core group of students was responsible for most of the project from meeting the client and user and estimating the construction cost to design and construction. Extensive material research was conducted to understand both the potential and limit of the material. Full-scale mockups of bamboo joints were made to test students' craftsmanship, and to experience a first-hand feel of the weight of the material (Fig. 7-10). 


\section{Knowledge Gained through Educational Making Projects}

\section{Parametric Design \& Digital Fabrication $\neq$ Automated Construction}

Although automated construction is already widely in practice in smaller-scale manufactures, such as cars and electronic products, automated construction in the building industry has yet to be commercialised. Advanced design and fabrication tools are becoming highly affordable and accessible for professionals as well as students. Almost anyone can design and fabricate something with complex geometry or patterns at the domestic scale. However, fullscale construction and assembly of architectural elements still largely depends on manual labour, on or off site. The experience of making these projects taught the students that in order to realise architecture, understanding of material properties, fabrication and the assembly process is crucial.

The Tamar Project is a collaborative project with the Environmental Bureau to design and build a park installation out of recycled wooden palettes. The project was embedded into a design studio that looked at parametric design and fabrication. The design concept was to disassemble the palette and reassemble the timber planks into park furniture that serves as benches for visitors. Rectangular planks were cut at 45 degrees at both ends to create a three-dimensional zigzag pattern. What appeared to be a fairly simple material manipulation in the digital model transformed into a huge construction challenge for the students, requiring over two hundred man-hours of material preparation and prefabrication.

The Very Hong Kong project was done within the same digital design studio as a collaboration with the Very Hong Kong Foundation which sponsored the fabrication of the project. The team had the flexibility to choose the desired material under the given budget and timeframe. The Very Hong Kong (VHK) project had another advantage over the Tamar project in that the team had sufficient budget to hire a contractor for the prefabrication work. Learning from the other team's struggles, the VHK team understood how the component design could optimise the construction and assembly sequence. In the final design, students simplified the construction. They reduced the variations of components from eleven to six. Designers modified component size to reduce their total number, and designed them as an interlocking system to reduce the number of fixtures required for on-site assembly.

\section{Part-to-Whole vs. Whole-to-Part}

A close comparison between the Manual project and the Digital project reveals two different ways of design thinking commonly seen, namely the part-to-whole approach and the whole-to-part approach. With the Oil Street and Meinan Pavilion bamboo projects, research on the construction detail of the bamboo joints was the first priority. The design process can only begin when students have a clear idea of what they are able to do with the material. With the Very Hong Kong and Tamar Park Installation, although the project briefs required the students to generate the design based on repetition and variation of a 3D pattern module, the construction and assembly detail of the parts was largely an afterthought informed by the formal composition of the overall design. At the beginning, when students worked on the bamboo projects, they had little idea what the final design might be. The image of the final piece gradually came to light as the making and testing of material went along. In contrast, students who worked on the Very Hong Kong and Tamar projects had clear ideas about the final design in the early stage, despite the fact that the schemes were not material-specific. Most of the detail design came after the design was finalised with the chosen material. 
The part-to-whole approach challenges our students' preconception that design is a linear process from drawing to planning to making. In the Oil Street project, there was hardly the need to draw. Tutors and students tested and discussed the design through direct interaction with the material, body, and context. The Meinan Pavilion's dynamic design process blended drawing, planning, and making together. Students made drawings to represent the pavilion design, as well as a construction manual for fellow students participating in the workshop. The team regularly constructed mock-ups to ensure buildability. The project team needed to pre-order materials for the two-week workshop, forcing the team to detail the design as thoroughly as they could. Once they started on-site construction, the team could automatically redesign details to address problems.

\section{Interchangeable Design}

In contemporary architecture, flexibility and interchangeability are important design constraints. Architects and their clients no longer expect architecture to last forever, but instead, to accommodate alteration, extension, and transformation in order to suit new capacity, purpose, and functions. The systematic approach in computational design forces students to clearly identify the variety of parameters in the design, allowing students to exercise more control in the process and evaluate the relationships between the variables and the constants. The project team designed the Very Hong Kong installation for easy modification in terms of material, scale, and formal composition. On the other hand, the empirical approach in non-computational design encourages students to design in a more intuitive environment. Often there are more surprises towards the end of the project because the design process is still active during the construction stage.

\section{Interactive Design}

As mentioned above, it is critical that students test and evaluate their design in actual situations. When the students are simultaneously in the roles of the fabricators and builders of their own project, testing and evaluation become integral parts of the design process. During construction, students are constantly examining the design with their bodies, experiencing spaces in light, rain, and wind. With their own hands, they connect with the materiality of the elements that put together the architecture. It is through physical engagement in building/making that they truly understand human, material, and nature. Students wanted to modify the design or to resolve a particular detail not because of an external comment, but because of the instinctive nature of a designer who works to perfection. Such design, fabricate, and build experience is difficult to provide in a normal studio environment. This will undoubtedly enable the next-generation of architects to acquire more comprehensive design knowledge at school. It will also open up new design methodologies that allow a more intuitive approach to computational design.

\section{Conclusion}

Computational design, digital fabrication and automated construction will play a significant role in the architecture industry. These tools enrich our experience in actualising our design concepts and enable us to design and construct with everincreasing possibility, precision, and efficiency. Currently, computational tools can help us iterate through pattern, composition, or form, analyse structural, environmental, and cost performance, and fabricate, through 3D printing in concrete, metal, glass, or others. Yet we value the hands-on experiential process that connects us to the long history of design and making. Outside design pedagogy, some of these hands-on skillsets will remain relevant for a long time, in environments 
where technology and skill are constrained. This writing serves an interval summary and review of how the HKDI architecture program utilised live projects as an educational tool to equip our students with the relevant abilities and mindsets. In the future, we will continue to enhance the Design-Fabricate-Build experience as an important part of our pedagogy as we believe it is only through this full cycle of actualisation that the intimacy between an architect and his or her architecture can grow.

Table 1: Digital and manual design methodologies in exemplary design-fabricate-build projects shown.

\begin{tabular}{|c|c|c|c|c|}
\hline $\begin{array}{l}\text { Project } \\
\text { (in chronological order) }\end{array}$ & Schematic Design & Detail Design & Fabrication & Assembly \\
\hline $\begin{array}{l}\text { Oil Street Bamboo } \\
\text { Installation }\end{array}$ & $\mathbf{M}$ & $\mathbf{M}$ & $\mathbf{M}$ & M \\
\hline Halo Modular Unit & $\mathrm{D}+\mathrm{M}$ & $\mathrm{D}$ & $\mathrm{D}+\mathrm{M}$ & $\mathbf{M}$ \\
\hline $\begin{array}{l}\text { Very Hong Kong } \\
\text { Installation }\end{array}$ & $\mathrm{D}$ & $\mathrm{D}$ & $\mathrm{D}$ & $\mathbf{M}$ \\
\hline $\begin{array}{l}\text { Tamar Park } \\
\text { Installation }\end{array}$ & $\mathrm{D}$ & $\mathrm{D}$ & $\mathbf{M}$ & $\mathbf{M}$ \\
\hline $\begin{array}{l}\text { Meinan Village } \\
\text { Bamboo Pavilion }\end{array}$ & $\mathbf{M}$ & $\mathbf{M}$ & $\mathbf{M}$ & $\mathbf{M}$ \\
\hline
\end{tabular}



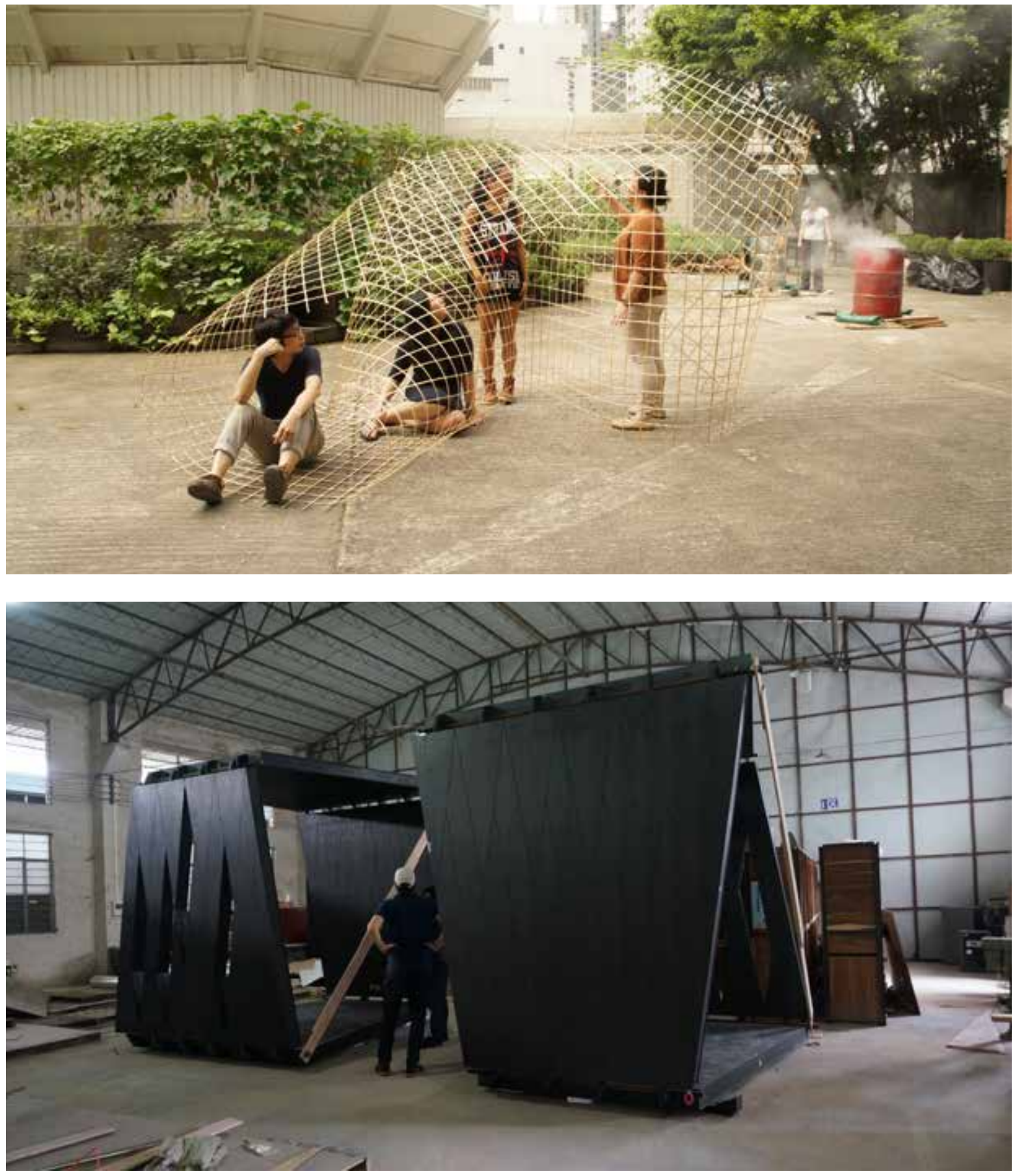


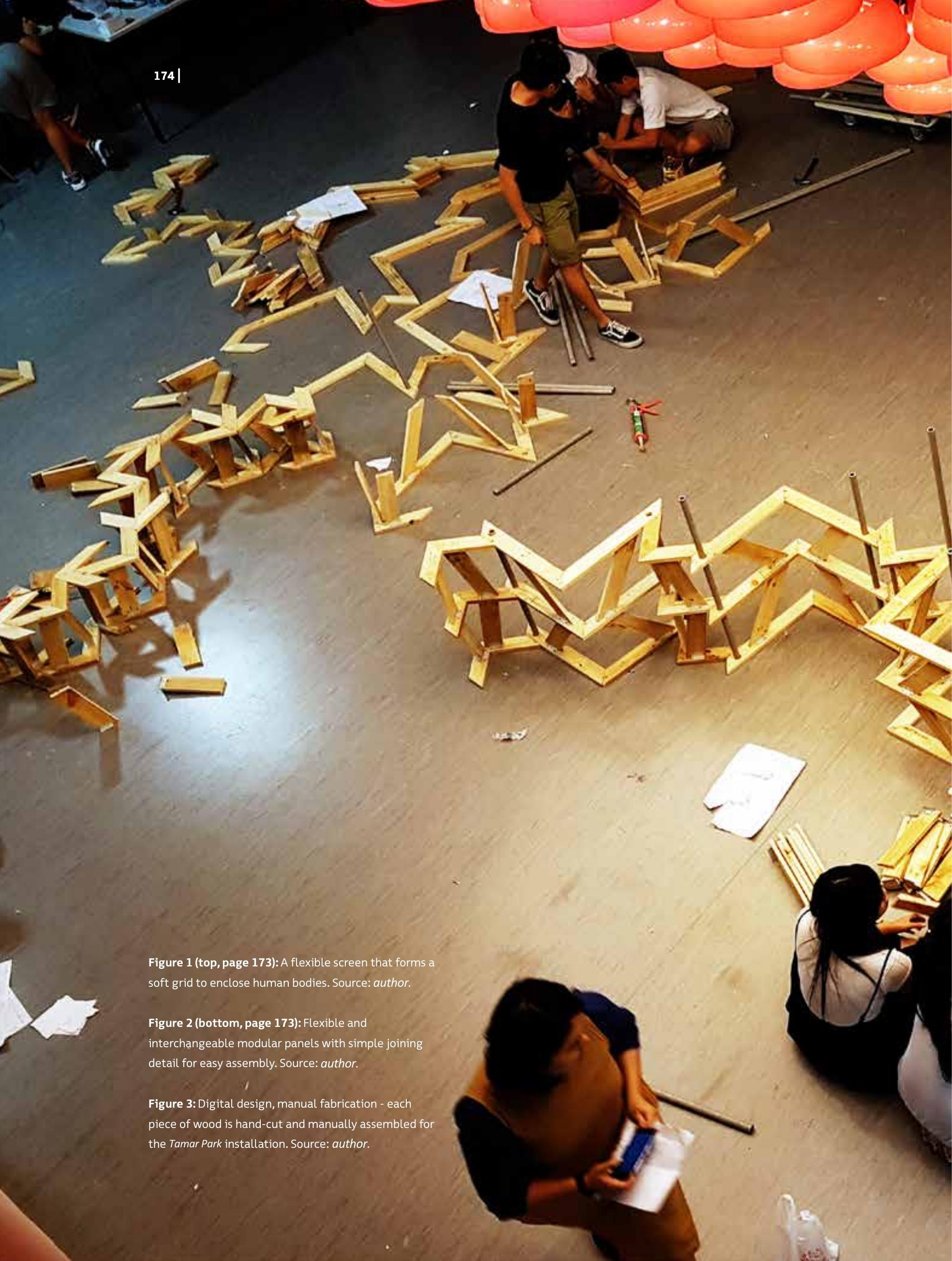




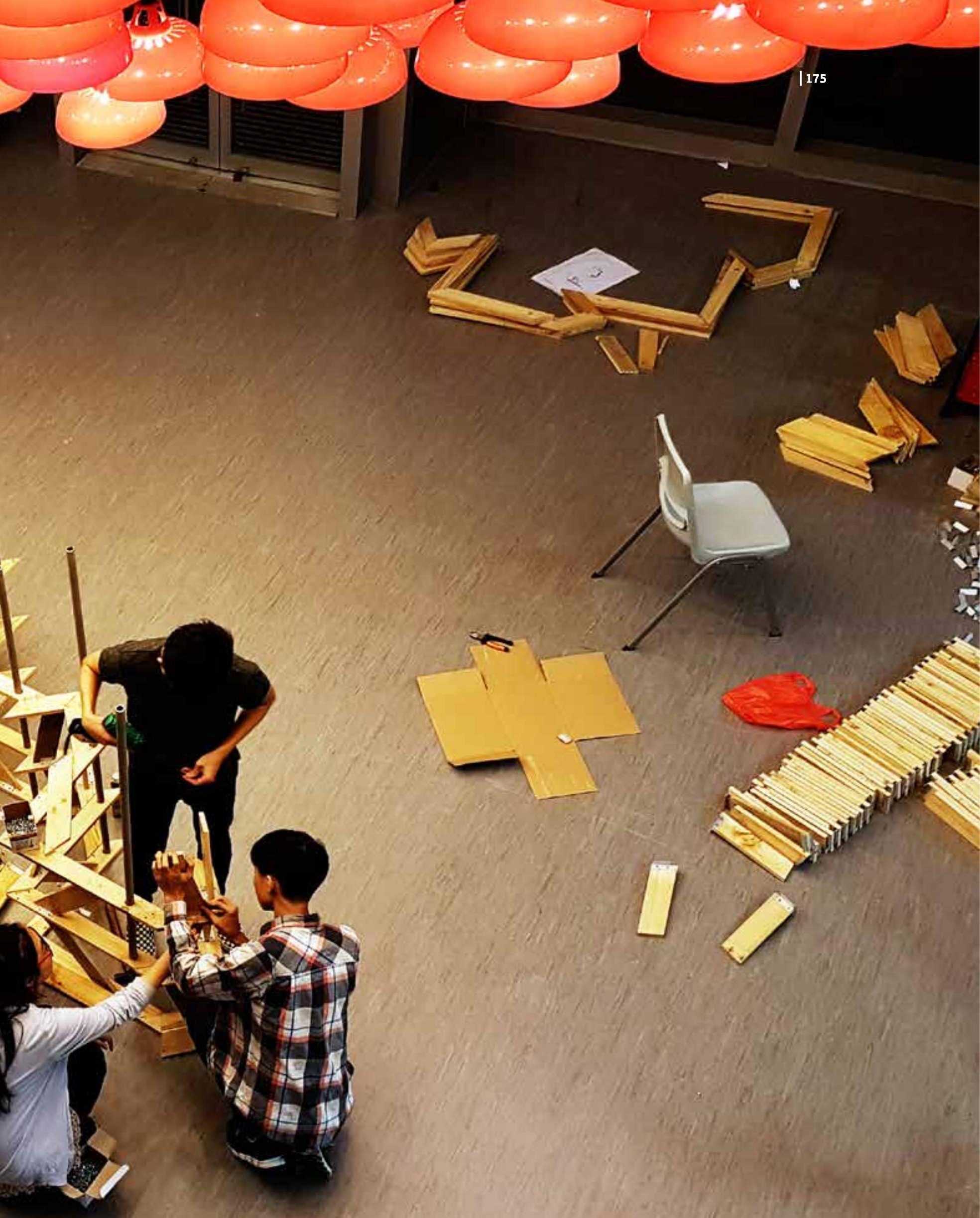




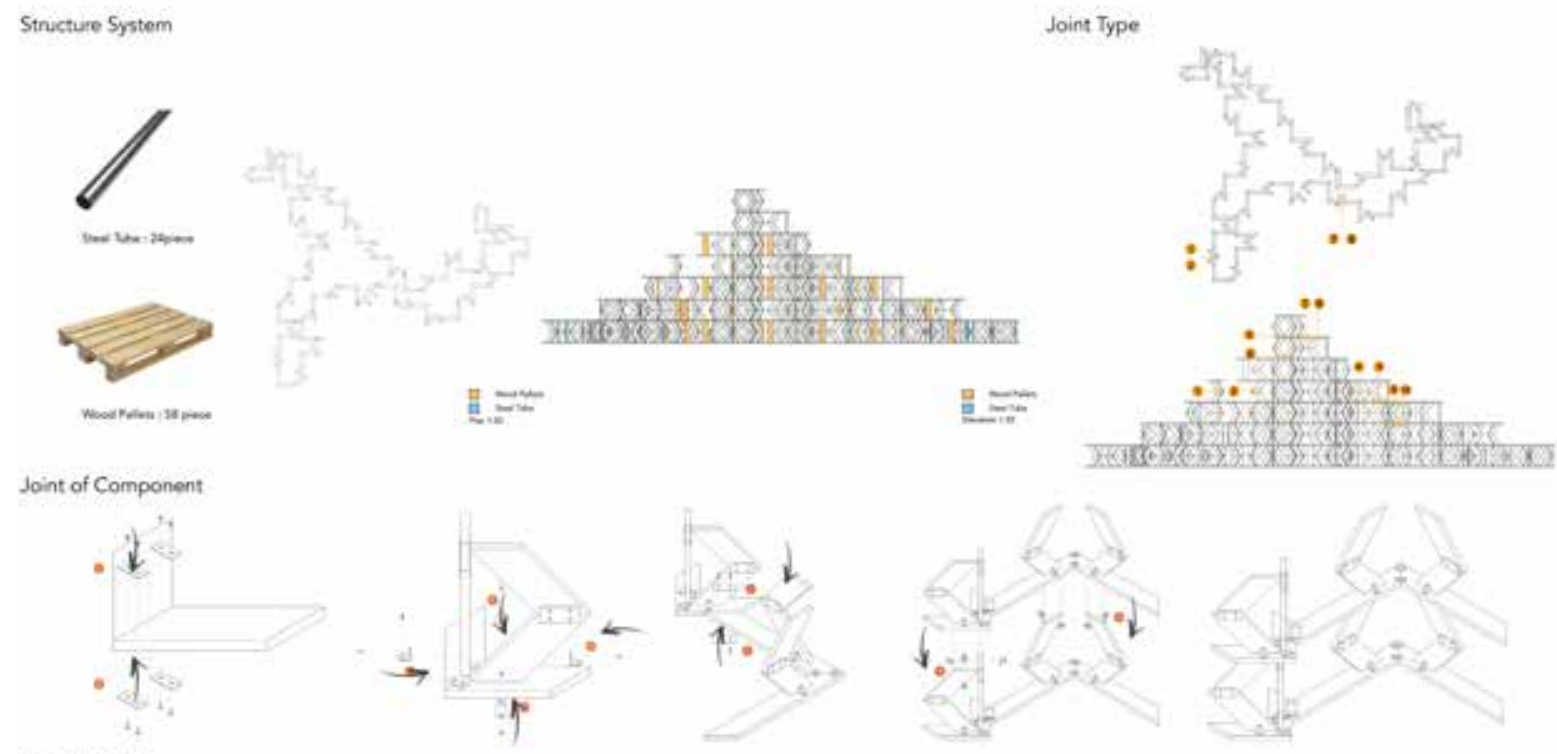

Joint of Detail

\section{Construction Analysis}
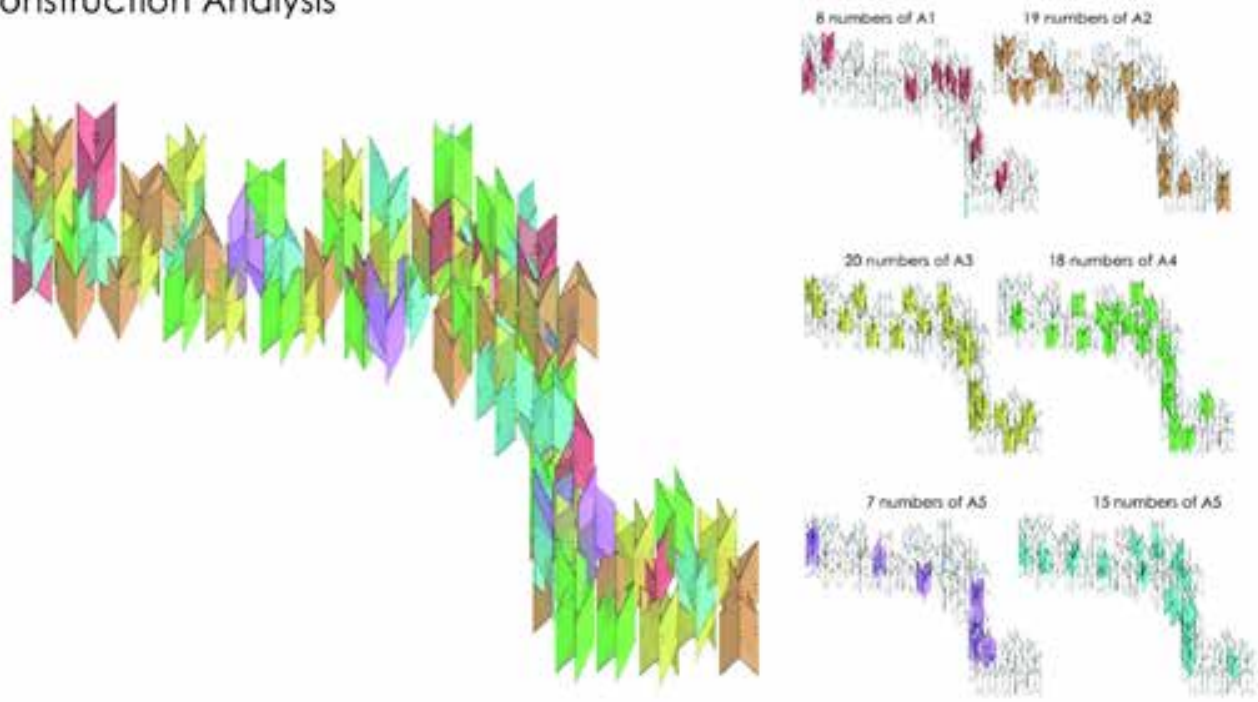

Figure 4 (top): Design concept of the component and the installation. Source: author.
Figure 6 (opposite page): Components categorised and assembled as a three-dimensional puzzle. Source: author.

Figure 5 (bottom): Organisation diagram of the six variations of the component. Source: author. 


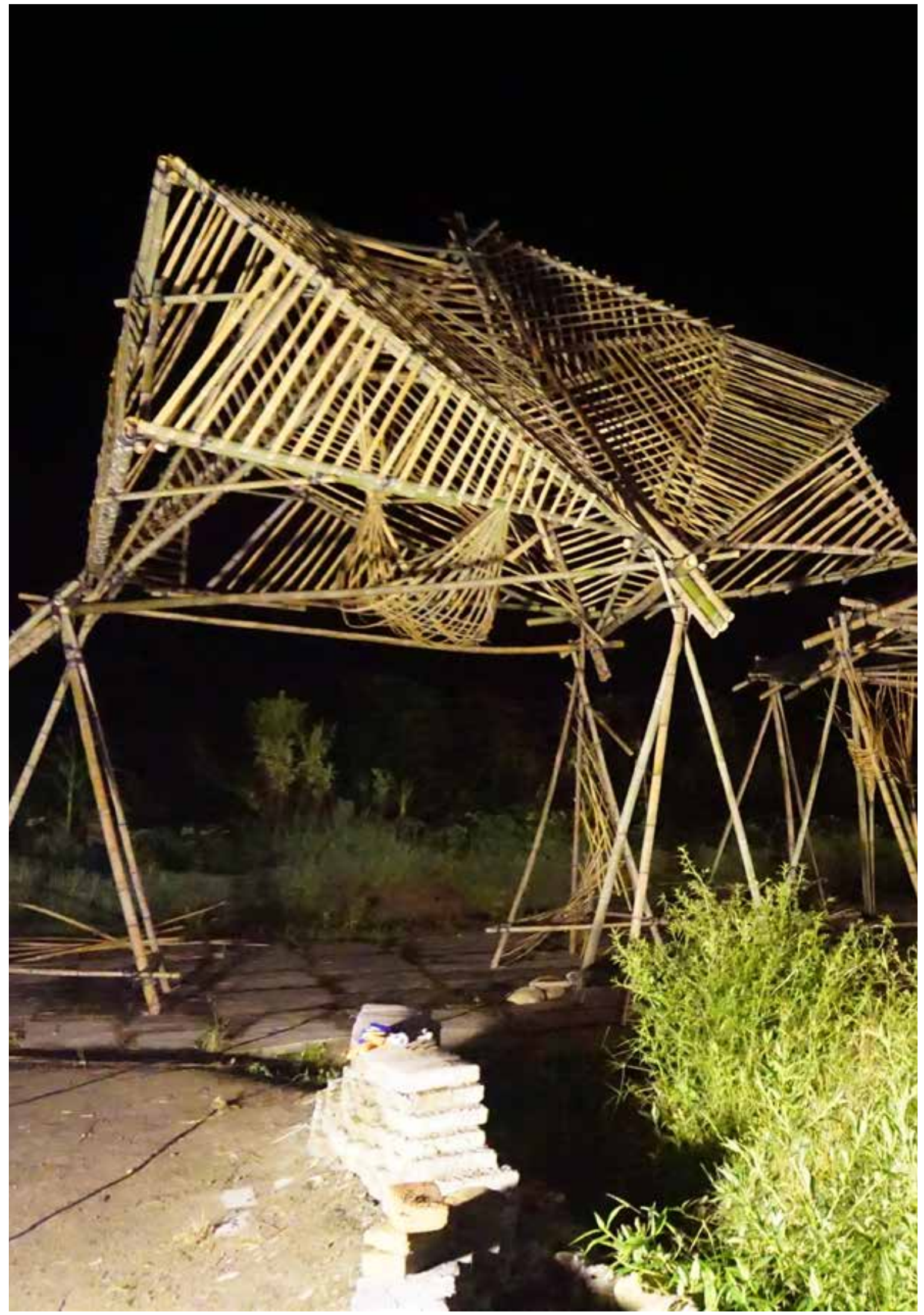




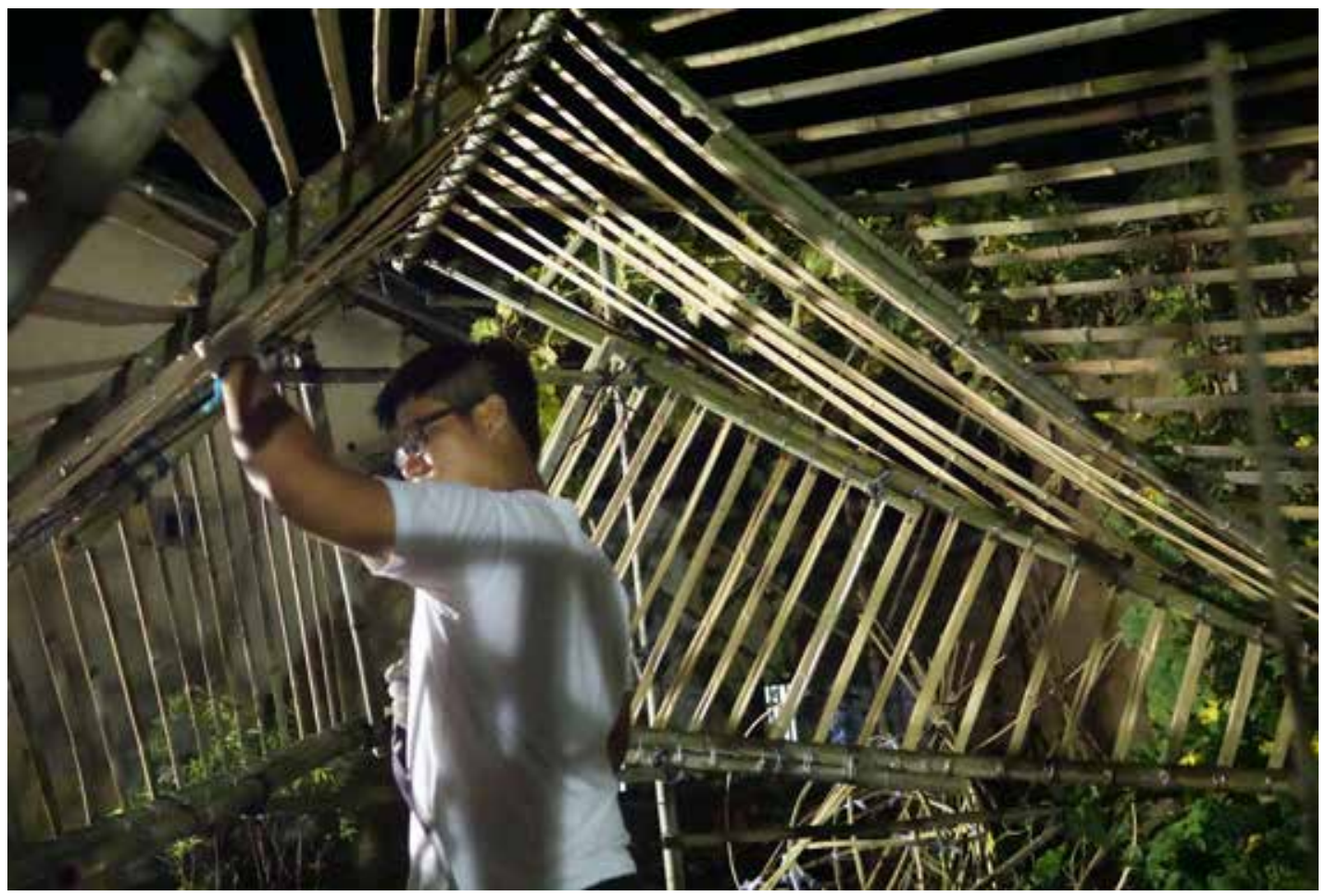

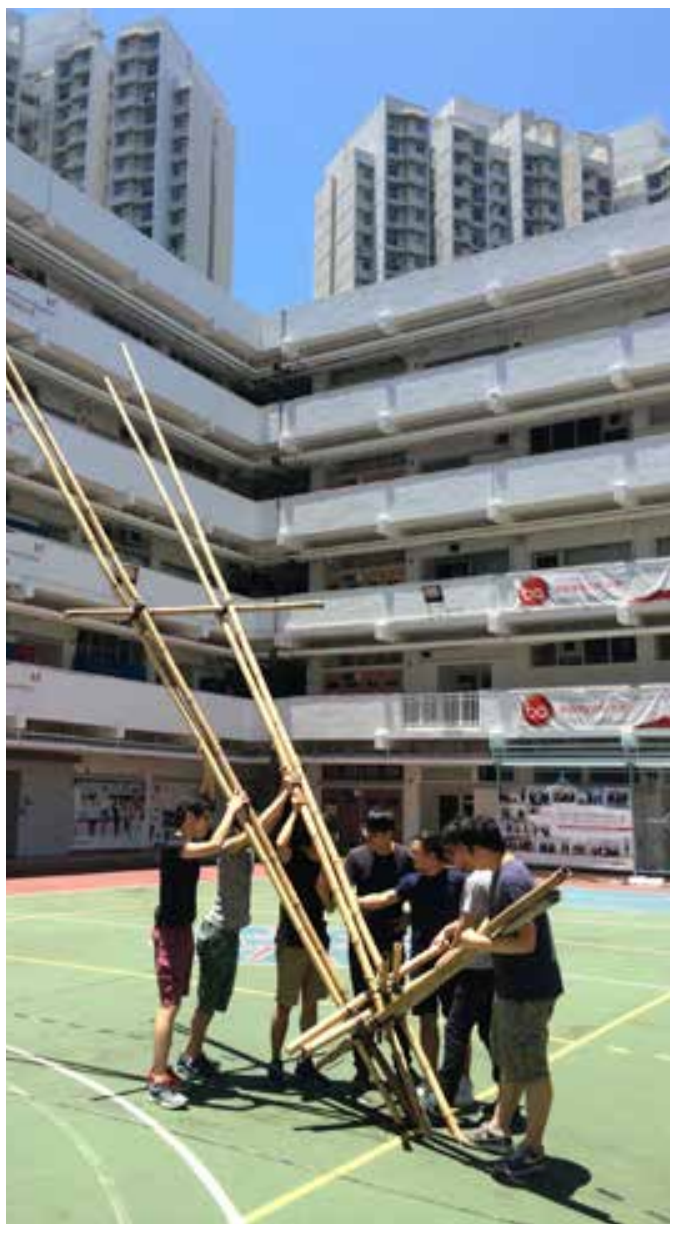

Figure 7 (opposite page): Bamboo pavilions designed in a variety of roof forms and permeability with standardised pillars that defined the activity zones on the ground. Source: author

Figure 8 (left): Meinan Village Bamboo Pavilion Full-scale mock-up. Source: author.

Figure 9 (top): Continuous testing and modification of the shading screen during construction. Source: author.

Figure 10 (page 180): In the Meinan Village Bamboo Pavilion human activity is an intuitive response to the environment. Spatial understanding becomes experiential through activity. Source: author. 


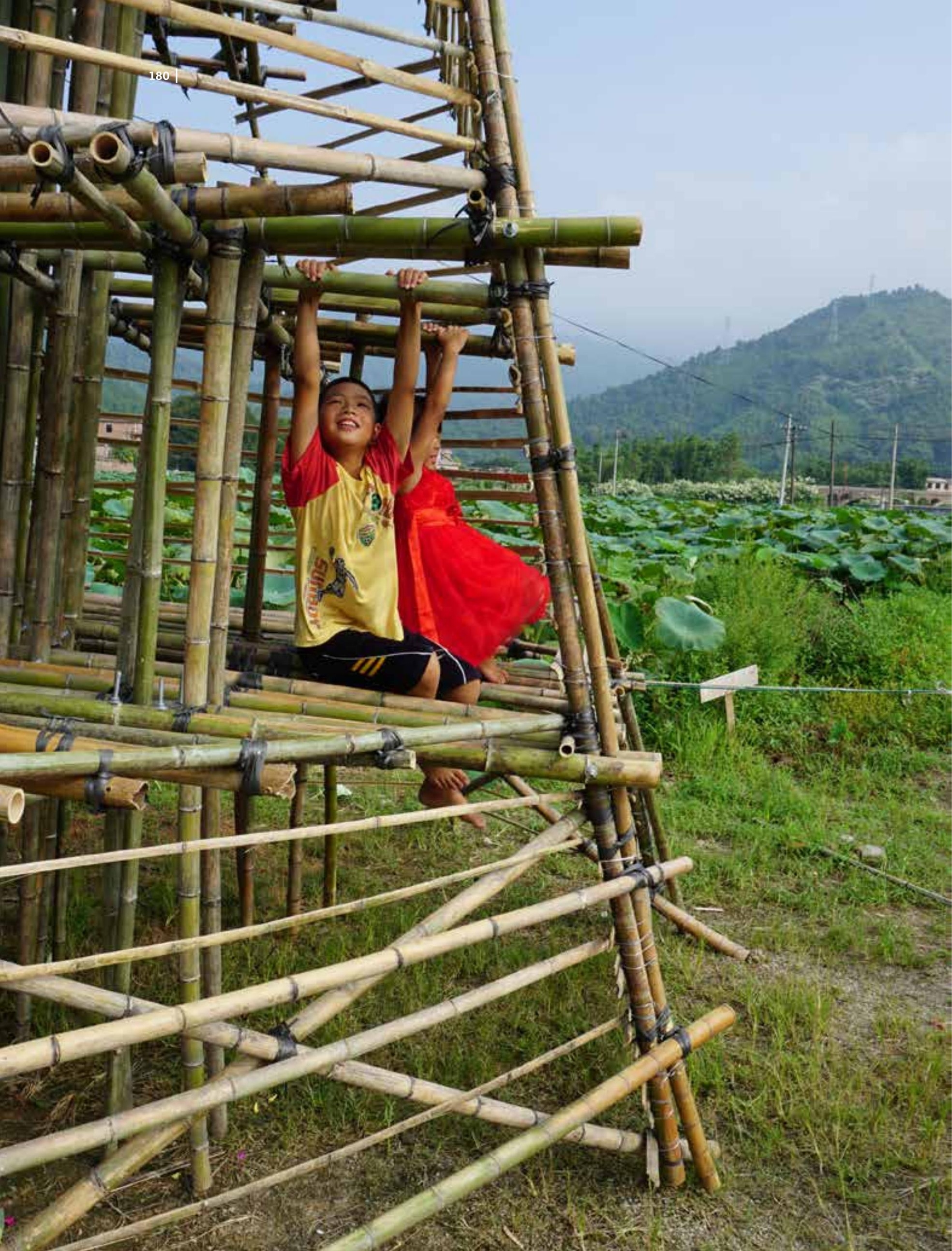




\section{Bibliography}

Bellini, Mario. 'What's New', Public Lecture, Business of Design Week (BODW). Hong Kong. 24 October 2017.

Evans, Robin. 1996. Translations from Drawings to Building and Other Essays. Architectural Association Publication.

Pallasmaa, Juhani. 2009. The Thinking Hand: Existential and Embodied Wisdom in Architecture. John Wiley \& Sons.

Salter, Peter. 1989. Themes VI: T.S. Intuition \& Process. Architectural Association.

\section{Bio}

Eddie Chan received his architectural education at the Architectural Association and the University of East London before returning to Hong Kong. After practising at architecture offices such as the Ronald Lu \& Partners and the Oval Partnership, Chan continued his career as a full-time lecturer of the Architectural Design Programme at the Hong Kong Design Institute where he has been since 2013. His work includes architecture, exhibition design, furniture design, curatorship and community engagement activities. 